\title{
Structural Analysis of Cotton/Lycra Corespun Single Jersey Knitted Fabrics
}

Kathirvel KP ${ }^{1 *}$ and Ramachandran $\mathrm{T}^{2}$

${ }^{1}$ Department of Textile Technology, KSR College Technology, Tiruchengode, Tamil Nadu, India

${ }^{2}$ Karpagam Institute of Technology, Coimbatore, Tamil Nadu, India

\begin{abstract}
An attempt has been made to analyze the effect and as well as to gain an insight of changing the loop length of the knitted fabric against non-dimensional parameters such as the loop shape factor during different stages of relaxation using corespun cotton/lycra yarn. The yarn count, machine gauge and machine diameter are kept constant but the loop length is varied. Three different structures (Popcorn, Double Airtex and Honeycomb) at 0.106 , 0.118 and 0.129 inches loop length for each structure are produced. This study will help to analyze the relationship between loop length and the non-dimensional parameters like $\mathrm{K}_{\mathrm{c}}, \mathrm{K}_{\mathrm{w}}, \mathrm{S}, \mathrm{K}_{\mathrm{c}} / \mathrm{K}_{\mathrm{w}}$

Statistical analysis is done to analyze if there is any significant change in loop shape factor between different relaxed stages and between different loop lengths in a particular fabric structure.
\end{abstract}

Keywords: Loop length; Loop shape factor; Core spun yarn; Dry relaxed state; Wet relaxed state; Fully relaxed state

\section{Introduction}

Lycra/Cotton garments find numerous applications in knitwear industry and in this study the corespun yarn is used with Lycra in the core and Cotton forming the sheath. The advantage of using corespun (core cover) instead of plaiting technique where cotton and lycra are fed separately is that the loop formation of corespun yarn is better than plaited yarn [1]. The ability of the corespun knitted fabric to maintain the dimensional stability and loop shape factor is studied for three different structures with 3 different loop length and the results are discussed in this study [2-5]. In accordance to Munden [6] the dimensions of the relaxed fabrics in most of the simple weft knitted fabrics are solely determined by the length of yarn in the knitted loop. Munden recognized two relaxed states, namely a Dry relaxed state, taken up after some day's exposure to air and a wet relaxed state, taken up after soaking in water. Nutting [7] has shown that the wet relaxation process is irreversible, but the fabric dimensions depend upon water temperature used for relaxation and the regain of the fabrics when they are measured. The use of single dry or wet relaxed state is not only convenient but a necessary simplification.

As the determination of loop length and dimensional parameters are of prime importance in defining the end use of the knitted fabrics, the present study is the continuation of the earlier studies in this field. So the objective of this research work is to establish the dimensional constants of three samples and to investigate the effect of loop length on non-dimensional parameters in different relaxed states.

\section{Materials and Methods}

The experimental part of this study involves corespun yarn having lycra in the core and cotton in the sheath of 30's Ne was purchased from M/s.Arunachala Gounder Textiles, Pallipalayam, Erode district. The yarn count was measured in indirect system and the test results are shown in table 1.

The yarn samples are tested to find unevenness and imperfections on an Uster-UT3 evenness tester using testing speed of $100 \mathrm{~m} / \mathrm{min}$ and time $3 \mathrm{~min}$. The results are shown in table 2.

\section{Preparation of fabric samples}

The fabric was knitted on PAI LUNG circular knitting machine. The machine specifications are given below.

Number of needles: 1800, Machine speed: $15 \mathrm{rpm}$, Gauge: 24, Cylinder Dia: 24 inches Number of feeders: 72, Model and Make: FS3B and PAI LUNG, Needle type: Latch.

Three types of weft knit structures with three different loop lengths each were produced (Figure 1).

\section{Methodology}

Knitted fabrics are similar to woven fabrics in that they are subject to relaxation shrinkage. However, it has been found difficult experimentally to determine when a fabric has reached a totally relaxed

\begin{tabular}{|c|c|}
\hline NOMINAL COUNT & Ne 30/1 \\
\hline ACTUAL COUNT & 29.98 \\
\hline COUNT CV\% & 1.07 \\
\hline BLEND & COMBED COTTON/LYCRA \\
\hline SPANDEX DENIER & Z D \\
\hline TWIST DIRECTION & 93.5 \\
\hline COTTON\% & 6.5 \\
\hline LYCRA\% & 853 \\
\hline Twist Per Metre SINGLE & \\
\hline
\end{tabular}

Table 1: Yarn test results.

\begin{tabular}{|c|c|}
\hline \multicolumn{2}{|c|}{ USTER RESULT } \\
\hline U\% & 9.31 \\
\hline THIN $(-50 \%)$ & 0.8 \\
\hline THICK $(+50 \%)$ & 11.8 \\
\hline NEPS $(+200 \%)$ & 21.3 \\
\hline TOTAL IMPERFECTIONS & 33.9 \\
\hline
\end{tabular}

Table 2: Evenness test result.

*Corresponding author: Kathirvel KP, Department of Textile Technology, KSR College Technology, Tiruchengode, Tamil Nadu, India, E-mail: kpkvelu@gmail.com

Received December 31, 2012; Accepted January 28, 2013; Published February 05, 2013

Citation: Kathirvel KP, Ramachandran T (2013) Structural Analysis of Cotton/ Lycra Corespun Single Jersey Knitted Fabrics. J Textile Sci Eng 3: 126. doi:10.4172/2165-8064.1000126

Copyright: @ 2013 Kathirvel KP, et al. This is an open-access article distributed under the terms of the Creative Commons Attribution License, which permits unrestricted use, distribution, and reproduction in any medium, provided the original author and source are credited. 


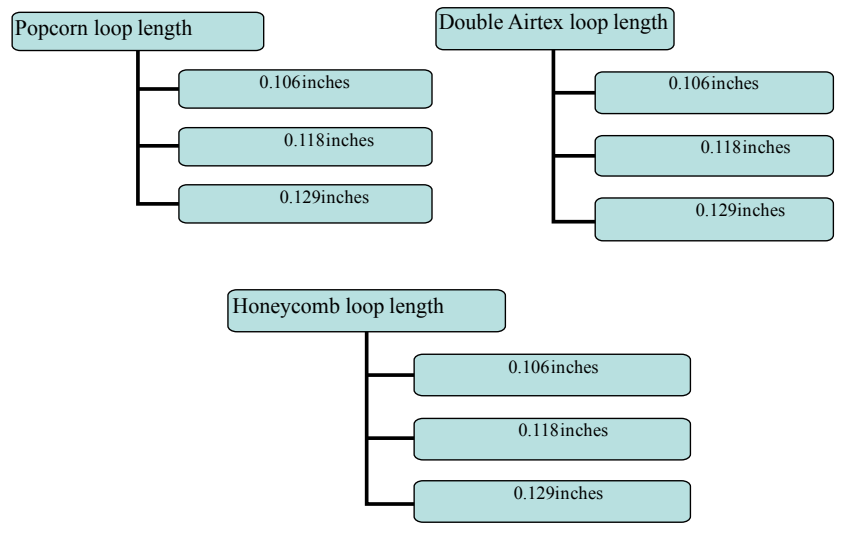

Figure 1: Types of weft knit structures with three different loop lengths each.

state in which it is in a stable sate with minimum energy. The fabric samples are subjected to the following relaxation treatments and the geometrical properties like wales per inch, course per inch are analyzed after each state of relaxation.

Dry Relaxed State (DRS): The fabric is relaxed in grey state under standard test conditions at $65 \pm 2 \% \mathrm{RH}$ and $27 \pm 2^{\circ} \mathrm{C}$ for two days.

Wet Relaxed State (WRS): This is achieved by subjecting the fabric to static soak with $0.7 \%$ wetting agent for one day and the fabric is allowed to relax for at least 3 days.

Heat Setting (HS): The fabric is stretched to the required level and set permanently by passing through the heating and curing chamber at $180^{\circ} \mathrm{C}$ for 40 seconds.

Bleaching: The fabric is treated with $0.7 \%$ wetting agent and to avoid creasing, $0.5 \%$ lubricant is added. Stabilizer of $0.3 \%$, Caustic Soda of $3 \%$ and Peroxide of $2.5 \%$ is added to the sample and the machine is run for one hour at $95^{\circ} \mathrm{C}$. After one hour the bath is drained and the machine is run with killer of $0.7 \%$ and acetic acid of $1.0 \%$ at $\mathrm{pH}$ of 6.5 and a temperature of $80^{\circ} \mathrm{C}$ for half an hour. Killer is used to remove peroxide and acetic acid is used for neutralization.

Dyeing (DY): The recipe for dyeing is Blue EDG of $0.90 \%$, Salt of $1.35 \mathrm{~g} / \mathrm{l}$, Soda ash of $20 \mathrm{gms}, \mathrm{M}: \mathrm{L}$ ratio is $1: 8$ and the temperature is $65^{\circ} \mathrm{C}$. The salt is added to obtain evenness of color throughout the fabric and soda ash is added to fix the color in the fabric.

Compacting (COM): It is done to stabilize the cotton yarn. The samples are compacted at $100^{\circ} \mathrm{C}$ for 30 seconds. The fabric is subjected to compressive shrinkage in the width direction.

The non directional parameters like $\mathrm{K}_{\mathrm{c}}$ (Course constant), $\mathrm{K}_{\mathrm{w}}$ (Wales constant), $\mathrm{S}$ (Stitch density), $\mathrm{K}_{\mathrm{s}}$ (Stitch density constant) and $\mathrm{K}_{\mathrm{c}} /$ $\mathrm{K}_{\mathrm{w}}$ (Loop shape factor) are calculated as per the formula given below.

$\mathrm{K}_{c}=$ Course per inch $\times$ loop length in inches.

$\mathrm{K}_{\mathrm{w}}=$ Wales per inch $\times$ loop length in inches.

$S=$ Course per inch $\times$ Wales per inch.

$\mathrm{K}_{\mathrm{s}}=\mathrm{S} \mathrm{x}$ (loop length in inches) ${ }^{2}$.

Loop shape factor $=\mathrm{K}_{\mathrm{c}} / \mathrm{K}_{\mathrm{w}}$.

\section{Results and Discussions}

\section{Relationship between loop length and loop shape factor}

It is established from figures 2-6 the loop shape factor $\left(\mathrm{K}_{\mathrm{c}} / \mathrm{K}_{\mathrm{w}}\right)$ for

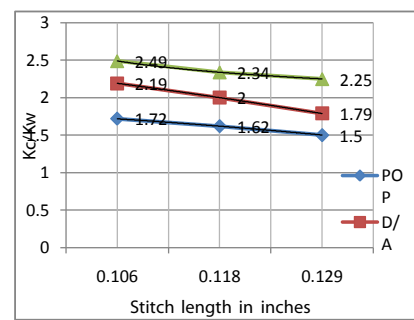

POPCORN: $Y=-0.01 x^{2}-0.16 x+2.36$

$R^{2}=1$

DOUBLE AIRTEX: $Y=-0.01 x^{2}-0.07 x+1.8$

$R^{2}=1$

HONEY COMB: $Y=-0.21 \ln (\mathrm{x})+2.490$

$R^{2}=1$

Figure 2: Loop Length vs Kc/Kw at DRS.
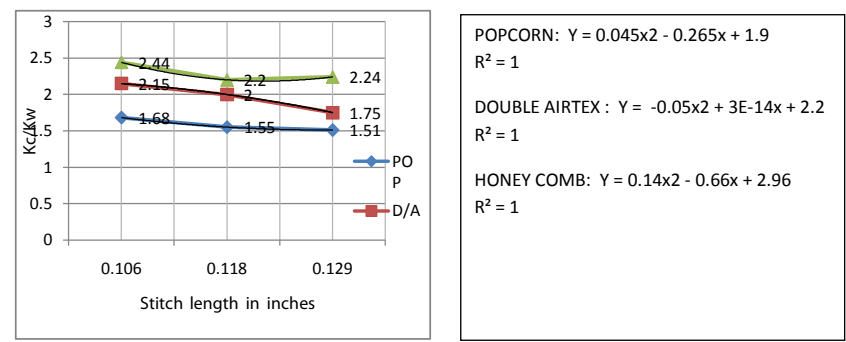

Figure 3: Loop Length vs $\mathrm{Kc} / \mathrm{Kw}$ at WRS.

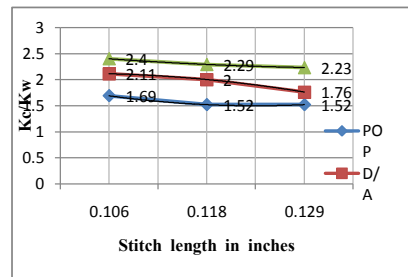

POPCORN: $Y=0.085 x^{2}-0.425 x+2.03$

$\mathrm{R}^{2}=1$

DOUBLE AIRTEX: $Y=-0.065 x^{2}+0.085 x+2.09$

$\mathrm{R}^{2}=1$

HONEY COMB: $Y=0.025 \times 2-0.185 x+2.56$

$R^{2}=1$

Figure 4: Loop Length vs Kc/Kw at Heatset Stage.

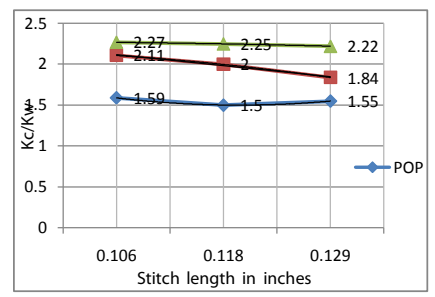

POPCORN: $Y=0.07 x^{2}-0.3 x+1.82$

$\mathrm{R}^{2}=1$

DOUBIEX: $Y=-0.025 x^{2}-0.035 x+2.17$

$\mathrm{R}^{2}=1$

HONEY COMB: $Y=-0.005 x^{2}-0.005 x+2.28$ $R^{2}=1$

Figure 5: Loop Length vs Kc/Kw at Dyed Stage.

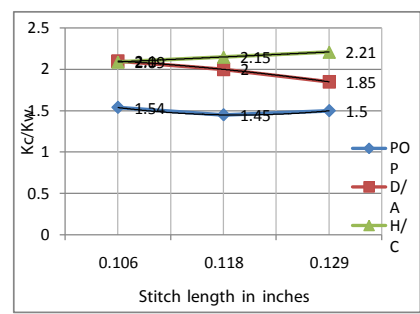

POPCORN: $Y=0.07 x^{2}-0.3 x+1.82$

$R^{2}=1$

DOUBLE AIRTEX: $\mathrm{Y}=-0.025 \mathrm{x}^{2}-0.035 \mathrm{x}+2.17$

$\mathrm{R}^{2}=1$

HONEY COMB: $Y=-0.005 x^{2}-0.005 x+2.28$

$R^{2}=1$

Figure 6: Loop Length vs Kc/Kw at Compacted Stage. 
each of the samples at different relaxed states reduces with increase in loop length which shows that loop shape is not maintained with increase in loop length. This shows that the fabric undergoes progressive length wise shrinkage, resulting in gradual decrease in course spacing. The analysis also shows that the loop shape factor for Honey comb structure is higher in all relaxed states, which is due to its stabilized structure.

\section{Relationship between loop length and aerial density}

From the test results it is observed that the aerial density increases after a sample is subjected to relaxation. This is due to the tendency of the yarn in a loop to try to regain its original shape after each relaxation stages. This is irrespective of the loop lengths and the value is higher in compacting stage because the fabric is subjected to compressive shrinkage in the lengthwise direction.

\section{Relationship between loop length and bursting strength}

From the observations it is known that the bursting strength increases after the fabric has completely relaxed because the course and wale density of the sample has increased from dry relaxed stage to compacted stage. But on comparison of the bursting strength in the same state, but with increase in loop length, it showed a reduction because of less stitch density. This trend is same on all samples.

\section{Relationship between loop length and thickness}

From the test results it is established that the thickness of the fabric reduces after different relaxation states for a particular loop length, which is due to the yarn attaining the maximum relaxed state of minimum residual energy. But as the loop length is increased the thickness is reduced which is obvious in a grey fabric. But after subsequent relaxation process the thickness is reduced.

\section{Regression analysis}

The regression analysis for the relationship between loop shape factor and loop length at different stages of relaxation are made and this is shown in each of the figures 2-6.

Statistical analysis of loop shape factor between loop length and different relaxed states using 2 WAY ANOVA (within structure) at $95 \%$ confidence level

\section{Popcorn}

Hypothesis 1: There is no significant difference in the loop shape factor between relaxed states.

Hypothesis 2: There is no significant difference in the loop shape factor between loop lengths.

$\mathrm{F}$ ratio between relaxed states is 6.3 and $\mathrm{F}$ ratio between loop lengths is 21.2

The calculated $\mathrm{F}$ value for both the conditions was more than the table value and hence both the hypothesis is rejected (Table 3).

The analysis showed that there is significant difference in the loop shape factor between relaxed states and loop lengths which imply that the loop length of the fabric sample is not able maintain its shape regardless of the different relaxation stages which is confirmed by the earlier work of Nutting [8].

\section{Double airtex}

Hypothesis 1: There is no significant difference in the loop shape factor between relaxed states.

\begin{tabular}{|c|c|c|c|c|c|c|c|c|c|c|c|c|c|c|c|}
\hline \multirow[t]{2}{*}{ Popcorn } & \multicolumn{5}{|c|}{0.106 inches } & \multicolumn{5}{|c|}{0.118 inches } & \multicolumn{5}{|c|}{0.129 inches } \\
\hline & DRS & WRS & HS & DY & COM & DRS & WRS & HS & DY & COM & DRS & WRS & HS & DY & COM \\
\hline Wales/nch & 36 & 38 & 40 & 44 & 48 & 34 & 36 & 38 & 40 & 44 & 32 & 33 & 34 & 36 & 40 \\
\hline Course/Inch & 62 & 64 & 68 & 70 & 74 & 55 & 56 & 58 & 60 & 64 & 48 & 50 & 52 & 56 & 60 \\
\hline $\mathbf{K}_{w}$ & 3.82 & 4.02 & 4.24 & 4.66 & 5.09 & 4.01 & 4.24 & 4.48 & 4.72 & 5.19 & 4.13 & 4.25 & 4.38 & 4.64 & 5.16 \\
\hline $\mathrm{K}_{\mathrm{c}}$ & 6.6 & 6.8 & 7.2 & 7.4 & 7.8 & 6.5 & 6.6 & 6.8 & 7.1 & 7.6 & 6.2 & 6.5 & 6.7 & 7.2 & 7.7 \\
\hline S & 2232 & 2432 & 2720 & 3080 & 3552 & 1870 & 2016 & 2204 & 2400 & 2816 & 1536 & 1650 & 1768 & 2016 & 2400 \\
\hline $\mathrm{K}_{\mathrm{s}}$ & 25.1 & 27.25 & 30.52 & 34.48 & 39.91 & 26.02 & 27.98 & 30.64 & 33.41 & 39.18 & 25.56 & 27.41 & 29.34 & 33.5 & 39.94 \\
\hline $\mathrm{K}_{\mathrm{c}} / \mathrm{K}_{\mathrm{w}}$ & 1.720 & 1.687 & 1.698 & 1.592 & 1.540 & 1.618 & 1.557 & 1.527 & 1.500 & 1.455 & 1.499 & 1.518 & 1.530 & 1.556 & 1.500 \\
\hline $\begin{array}{c}\text { Aerial density (Gms/square } \\
\text { metre) }\end{array}$ & 240 & 240 & 247 & 332 & 335 & 251 & 251 & 246 & 316 & 312 & 250 & 250 & 244 & 327 & 333 \\
\hline Bursting Strength $\left(\mathrm{Kg} / \mathrm{cm}^{2}\right)$ & 6.9 & - & - & - & 7.0 & 5.6 & - & - & - & 6.2 & 4.7 & - & - & - & 5.7 \\
\hline Thickness $(\mathrm{mm})$ & 0.62 & 0.62 & 0.85 & 0.83 & 0.76 & 0.76 & 0.76 & 0.92 & 0.88 & 0.77 & 0.79 & 0.79 & 0.98 & 0.94 & 0.88 \\
\hline
\end{tabular}

Table 3: Analysis of geometrical and non directional parameters of Popcorn Structure in different stages.

\begin{tabular}{|c|c|c|c|c|c|c|c|c|c|c|c|c|c|c|c|}
\hline \multirow[t]{2}{*}{ Double Airtex } & \multicolumn{5}{|c|}{0.106 inches } & \multicolumn{5}{|c|}{0.118 inches } & \multicolumn{5}{|c|}{0.129 inches } \\
\hline & DRS & WRS & HS & DY & COM & DRS & WRS & HS & DY & COM & DRS & WRS & HS & DY & COM \\
\hline Wales/Inch & 32 & 33 & 34 & 36 & 38 & 30 & 31 & 32 & 34 & 36 & 28 & 29 & 30 & 32 & 35 \\
\hline Course/Inch & 70 & 71 & 72 & 76 & 80 & 60 & 62 & 64 & 68 & 72 & 50 & 51 & 53 & 59 & 65 \\
\hline$K_{w}$ & 3.39 & 3.49 & 3.60 & 3.81 & 4.03 & 3.54 & 3.65 & 3.77 & 4.01 & 4.25 & 3.61 & 3.75 & 3.87 & 4.12 & 4.52 \\
\hline $\mathrm{K}_{\mathrm{c}}$ & 7.4 & 7.5 & 7.6 & 8.1 & 8.5 & 7.1 & 7.3 & 7.6 & 8.0 & 8.5 & 6.5 & 6.6 & 6.8 & 7.6 & 8.4 \\
\hline $\mathbf{S}$ & 2240 & 2343 & 2448 & 2736 & 3040 & 1800 & 1922 & 2048 & 2312 & 2592 & 1400 & 1479 & 1590 & 1888 & 2275 \\
\hline $\mathrm{K}_{\mathrm{s}}$ & 25.15 & 26.24 & 27.46 & 30.63 & 34.17 & 25.06 & 26.68 & 28.46 & 32.16 & 36.13 & 23.28 & 24.63 & 26.43 & 31.41 & 37.88 \\
\hline $\mathrm{K}_{\mathrm{c}} / \mathrm{K}_{\mathrm{w}}$ & 2.189 & 2.155 & 2.119 & 2.113 & 2.104 & 1.994 & 2.003 & 2.003 & 2.000 & 2.000 & 1.787 & 1.752 & 1.765 & 1.847 & 1.854 \\
\hline Aerial density (Gms/square metre & 295 & 295 & 280 & 357 & 348 & 292 & 292 & 279 & 361 & 377 & 288 & 288 & 272 & 321 & 374 \\
\hline Bursting Strength $\left(\mathrm{Kg} / \mathrm{cm}^{2}\right)$ & 6.2 & - & - & - & 7.1 & 5.0 & - & - & - & 6.2 & 4.3 & - & - & - & 5.4 \\
\hline Thickness $(\mathrm{mm})$ & 1.8 & 0.98 & 0.95 & 0.91 & 0.9 & 1.9 & 1.89 & 0.97 & 0.93 & 0.91 & 1.96 & 1.96 & 1.9 & 1 & 0.94 \\
\hline
\end{tabular}

Table 4: Analysis of geometrical and non directional parameters of Double Airtex structure in different stages. 
Citation: Kathirvel KP, Ramachandran T (2013) Structural Analysis of Cotton/Lycra Corespun Single Jersey Knitted Fabrics. J Textile Sci Eng 3: 126. doi:10.4172/2165-8064.1000126

Page 4 of 4

\begin{tabular}{|c|c|c|c|c|c|c|c|c|c|c|c|c|c|c|c|}
\hline \multirow[t]{2}{*}{ Honey Comb } & \multicolumn{5}{|c|}{0.106 inches } & \multicolumn{5}{|c|}{0.118 inches } & \multicolumn{5}{|c|}{0.129 inches } \\
\hline & DRS & WRS & HS & DY & COM & DRS & WRS & HS & DY & COM & DRS & WRS & HS & DY & COM \\
\hline Wales/Inch & 35 & 36 & 37 & 40 & 44 & 32 & 33 & 34 & 36 & 39 & 28 & 29 & 30 & 32 & 34 \\
\hline Coarse/Inch & 87 & 88 & 89 & 91 & 92 & 75 & 76 & 78 & 81 & 84 & 63 & 65 & 67 & 71 & 75 \\
\hline$K_{w}$ & 3.71 & 3.81 & 3.92 & 4.24 & 4.66 & 3.78 & 3.89 & 4.01 & 4.24 & 4.6 & 3.61 & 3.74 & 3.87 & 4.12 & 4.39 \\
\hline $\mathbf{K}_{\mathrm{c}}$ & 9.22 & 9.32 & 9.43 & 9.64 & 9.75 & 8.85 & 8.96 & 9.2 & 9.55 & 9.91 & 8.13 & 8.38 & 8.64 & 9.15 & 9.68 \\
\hline $\mathbf{S}$ & 3045 & 3168 & 3293 & 3640 & 4048 & 2400 & 2508 & 2652 & 2916 & 3276 & 1764 & 1885 & 2010 & 2272 & 2550 \\
\hline $\mathrm{K}_{\mathrm{s}}$ & 34.21 & 35.5 & 36.96 & 40.87 & 45.43 & 33.45 & 34.85 & 36.89 & 40.49 & 45.59 & 29.35 & 31.34 & 33.43 & 37.69 & 42.5 \\
\hline $\mathrm{K}_{\mathrm{c}} / \mathrm{K}_{\mathrm{w}}$ & 2.485 & 2.446 & 2.406 & 2.274 & 2.092 & 2.341 & 2.303 & 2.294 & 2.252 & 2.154 & 2.252 & 2.241 & 2.233 & 2.221 & 2.205 \\
\hline Aerial density (Gms/square metre & 286 & 286 & 295 & 381 & 372 & 290 & 290 & 291 & 391 & 389 & 297 & 297 & 275 & 363 & 393 \\
\hline Bursting Strength $\left(\mathrm{Kg} / \mathrm{cm}^{2}\right)$ & 6.2 & - & - & - & 7.1 & 5.1 & - & - & - & 6.25 & 4.3 & - & - & - & 5.45 \\
\hline Thickness (mm) & 1.87 & 1.87 & 1.09 & 1.07 & 0.98 & 1.92 & 1.92 & 1.1 & 1.08 & 1.04 & 1.97 & 1.97 & 1.11 & 1.02 & 1.09 \\
\hline
\end{tabular}

Table 5: Analysis of geometrical and non directional parameters of Honeycomb structure in different stages.

Hypothesis 2: There is no significant difference in the loop shape factor between loop lengths.

$\mathrm{F}$ ratio between relaxed states is 0.45 and $\mathrm{F}$ ratio between loop lengths is 99.6

The calculated F value between relaxed state was less than the table value and hence hypothesis 1 is accepted and the calculated $F$ value between loop length was more than the table value and hence hypothesis 2 is rejected. The possibility of significant difference between loop shape factor and relaxed states is due to its complexity of the structure of the sample which is reflected in the increase in loop length against loop shape factor (Table 4).

\section{Honeycomb}

Hypothesis 1: There is no significant difference in the loop shape factor between relaxed states.

Hypothesis 2: There is no significant difference in the loop shape factor between loop lengths.

$\mathrm{F}$ ratio between relaxed states is 0.19 and $\mathrm{F}$ ratio between loop lengths is 1.02

The calculated $\mathrm{F}$ value between relaxed state and between loop lengths was less than the table value and hence both the Hypothesis is accepted. This result shows that there is no significant difference in the loop shape factor between loop lengths and different relaxed states (Table 5). This is due to torsional resistance of the yarn and more balanced structure of the sample.

\section{References}

1. Spandex fibres-Scope and application. SITRA focus 20: 5-8.

2. Marmarali AB (2003) Dimensional and Physical Properties of Cotton/Spandex Single Jersey Fabrics. Text Res J 73: 11-14.

3. Keshkari KR (2002) Effect of yarn feed length on cotton weft knitted fabrics. The Indian textile Journal 131-136.

4. Mukhopadhyay A, Sharma IC, Mohanty A (2003) Impact of lycra filament on extension and recovery characteristics of cotton knitted fabric. Indian J Fibre Text 28: 423-430.

5. Thangamani K, Natarajan V (2003) Dimensional Stability of Polyester/Lycra Aircovered Yarn, Knitted Fabrics. 2nd Indo-Czech Textile Research Conference.

6. Munden DL (1959) The Geometry and Dimensional Properties of Plain-Knit Fabrics. J Text I 50: T448-T471.

7. Nutting TS (1961) Changes in the dimensions of plain-knitted wool fabrics with variations of moisture regain. J Text Inst 52: 407-415.

8. Nutting TS, Leaf GAV (1964) A Generalized Geometry of Weft-Knitted Fabrics. J Text I 55: T45-T53. 